\title{
Influencia alemana en la industria de Boyacá [Colombia]
}

SELECCIÓn SEMinARio InTERnACIONAL DE ESTUdios DEL PATRimonio IndUSTRIAL Armando Muñoz Luque

Arquitecto. Docente de la Universidad Santo Tomás, seccional Tunja. Especialista en Docencia Universitaria. Tunja [Boyacá] Colombia. <armando.munoz@usantoto.edu.co>

\section{Resumen}

En un momento de la historia del país en el que se encontraba en una crisis económica y atraso tecnológico, la presencia alemana en Boyacá tuvo gran importancia para el desarrollo del departamento gracias a los ingenieros y técnicos que aportaron en la minería, los teléfonos, la electricidad, la industria etc. Es de destacar que aquellos aportes alemanes fueron básicamente el maquinaria y equipos, de tal calidad, que aún hoy se siguen utilizando. Se destaca el caso de Acerías Paz del Río, una de las más importantes industrias del país, que aun es polo de desarrollo en el departamento, y cuya producción actual se debe en gran medida a los aportes de alemanes.

\section{Palabras clave}

Boyacá. Industria. Teléfonos. Electricidad. Siderúrgica. Paz del Río. Alemania.

\section{German influence on the industry of Boyaca [Colombia]}

\begin{abstract}
At one point in Colombian history when the new country was going through an economic crisis and was technologically backward, the German presence, particularly in Boyaca, had great importance for the development of the county, thanks to its engineers and technicians, who contributed to mining, telecommunications, electricity and overall burgeoning industry. It worth noting that those contributions were mainly in the way of German machinery and equipment, of such quality that even today they are still been used. The case of Acerias Paz del Rio, can be highlighted as one of the most important industries in the country, which is still a center of development in the county, and whose current production is largely due to German contributions.
\end{abstract}

\section{Keywords}

Boyaca. Industry. Telephones. Electricity. Steel plant. Paz del Rio. Germany. 


\section{Boyacá a fines del siglo XIX}

La finalización de la Guerra de los Mil Días coincidió con la terminación del siglo XIX y como consecuencia de ella, el país quedo en un estado lamentable de destrucción, ruina y atraso, a causa, no sólo de esta guerra, sino también de las innumerables guerras internas anteriores en las que se vio envuelta la nueva República. Algunos departamentos sufrieron en forma leve esta situación y no se vieron mayormente afectados pero otros quedaron estancados en su desarrollo o retrocedieron.

Boyacá que nunca se había distinguido por sus riquezas ni por sus adelantos tecnológicos o industriales se consideró en ese momento como uno de los departamentos más pobres y atrasados del país, ya que sus industrias no sobresalían o casi no existían y no tenía posibilidad de prosperar, pues el territorio carecía de riquezas mineras, sus vías eran aun incipientes y sus comunicaciones, rudimentarias ${ }^{1}$. Los gobiernos del siglo anterior, no habían hecho ningún esfuerzo para ayudar a esta región cuyo único mérito era ser la "Cuna de la Libertad".

La mayoría de las empresas públicas que operaban en Boyacá, prestaban un servicio muy deficiente porque no tenían la tecnología correspondiente a la época, estaban limitadas presupuestalmente y en una región tan extensa, era casi imposible dar cubrimiento a todos sus municipios, por lo que no llenaban las necesidades básicas de una población cada día más grande.

Las principales ciudades tenían plantas eléctricas de una capacidad mínima, escasamente para su iluminación; no había un sistema eléctrico interconectado de cobertura amplia, que pudiera unir todos los municipios, y el mismo problema se vivía con las comunicaciones telefónicas y terrestres, pues los teléfonos no cubrían todo el territorio y a los municipios a donde llegaba la señal se lograba mediante equipos ya caducos que hacían muy difícil la comunicación, en ocasiones imposible, entre la capital y los municipios o entre ellos mismos y otros departamentos. Igualmente las vías terrestres que disponía el departamento eran vías angostas, destapadas, peligrosas y que hacían que los desplazamientos fueran lentos, costosos y nada seguros.

\section{Teléfonos en Boyacá}

Los teléfonos se instalaron en Boyacá desde el 25 de noviembre de 1921, gracias a la Ley 41 del mismo año, operando con equipos alemanes marca DESTROYER, pero completamente desactualizados e inoperantes para la época y que no permitían su expansión, por lo que retrasaron el desarrollo de la región y la vinculación con el resto del país, en donde se contaba ya con equipos y tecnología de avanzada que los posesionaban por delante de Boyacá2.

Por esta razón, el 18 de enero de 1956, se suscribe el contrato entre la Gobernación del departamento y la firma alemana SIEMENS \& HALSKE, para la instalación de 13 plantas de teléfonos automáticos, las primeras en instalarse en Sur América. En Tunja se ubicó una planta de 2000 teléfonos, que se instaló en la antigua Telefónica del Departamento (hoy oficinas de El Tiempo). En Sogamoso, una planta con capacidad de 1259 abonados. En Duitama, una planta con 1000 teléfonos. En Chiquinquirá una planta con 200 teléfonos, Garagoa con 100 teléfonos, Guateque con 100 abonados, Moniquirá con 50 abonados, Santa Rosa de Viterbo con 50 teléfonos, Belén con 50 teléfonos, Soata con 50 teléfonos, Boavita con 50 abonados y El Cocuy con 50 teléfonos. Para la instalación y puesta en marcha de estas plantas vinieron al país ingenieros y técnicos alemanes, y para el manejo y mantenimiento permanente fueron enviados a Alemania funcionarios que trabajaban en la Telefónica de Boyacá, y que después formaron parte del grupo de funcionarios que manejarían todo el sistema telefónico.

Con la instalación de estas plantas, el servicio telefónico en Boyacá fue mejorado notablemente y los principales municipios del departamento quedaron enlazados con la red telefónica, ya que el contrato no se limitaba únicamente a la instalación de las plantas, sino que incluía el tendido de

\footnotetext{
${ }^{1}$ Historia de la industria en Colombia. Revista Trimestral de la Andi 11- 1970.

${ }^{2}$ Testimonio Sr. Anibal Cardozo, pensionado de Telecom, Julio de 2015.
} 
cables y la colocación de los respectivos postes, que fueron traídos directamente de Alemania y que en algunos lugares todavía se conservan. Al entrar a funcionar estos equipos, Boyacá fue considerada en ese momento como uno de los departamentos más avanzados en las comunicaciones telefónicas, en el contexto nacional. Cuando la Telefónica fue vendida a Telecom, estos equipos fueron trasladados e instalados en los municipios de Girardot y Zipaquirá3.

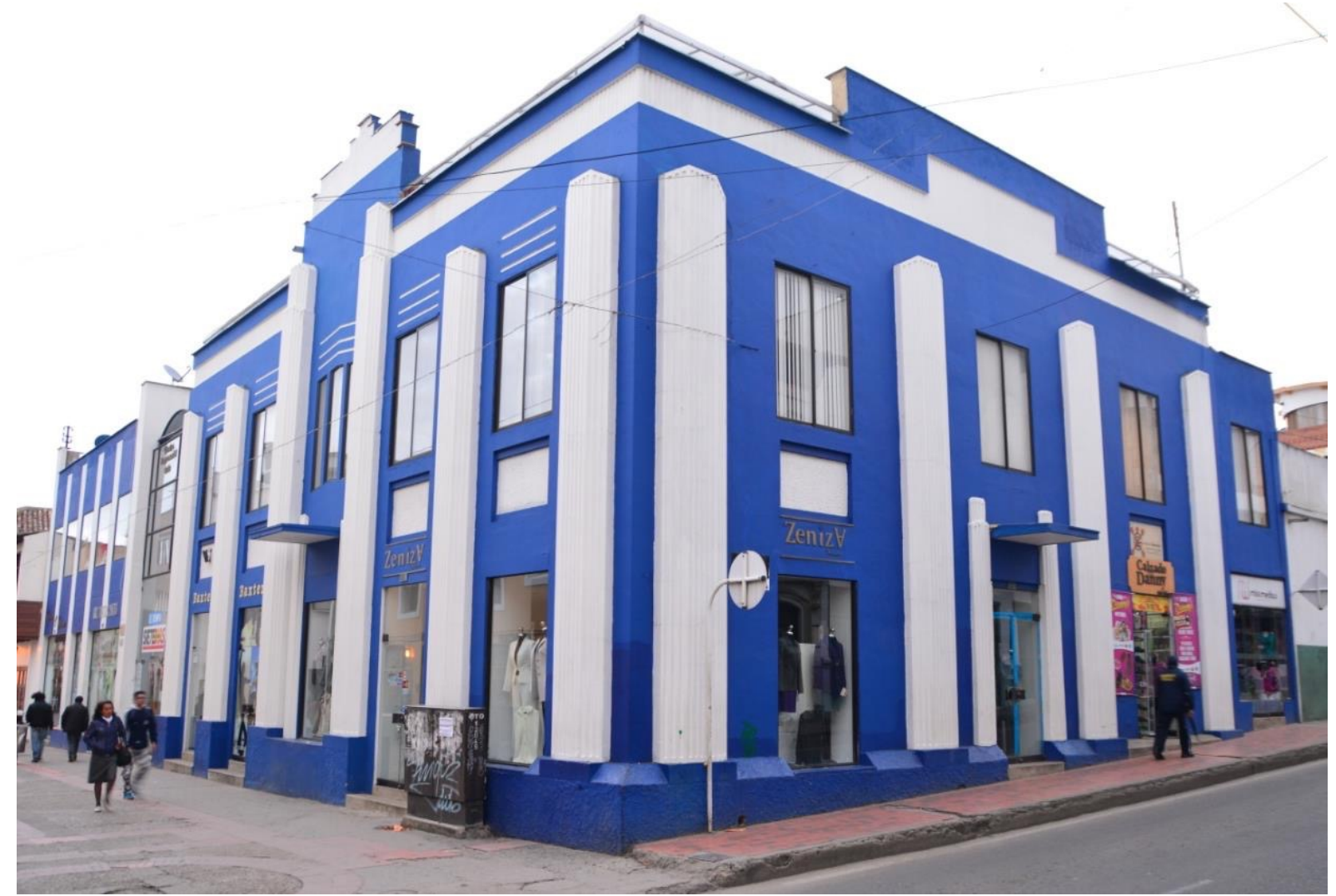

Figura 1. Edificio en Tunja de la antigua Telefónica Municipal donde se instalaron los equipos alemanes. Fuente: Armando Muñoz Luque.

\section{Electricidad en Boyacá}

El 4 de agosto de 1951, el entonces Gobernador de Boyacá, Carlos Arturo Torres anunció que para el mejoramiento de la electrificación de Tunja, y de siete municipios más, el departamento había contratado, en coordinación con el Instituto de Fomento Municipal, una planta TermoEléctrica que sería suficiente para mejorar el servicio de energía, tan deficiente, en la capital. Dicho contrato se firmó con la firma alemana Man de Núremberg, con lo cual se dio inicio a una etapa de prosperidad en cuestión de electrificación de los municipios. Al cabo de algunos años se dio inicio a la construcción de la red eléctrica definitiva, y así, en 1955, se instalaron en Tunja las calderas, una turbina y los tableros generales de la ya denominada Electrificadora de Boyacá, en el lote ubicado sobre la Avenida a Paipa con calle 48 (ver fotografía) y donde aún se conserva una edificación cuya construcción fue dirigida por los alemanes, en la cual se instalaron los equipos de la marca mencionada, importados de Alemania, que contribuyeron al desarrollo eléctrico del departamento con el aporte tecnológico de los técnicos e ingenieros que dirigieron estas obras.

Cuentan personas que trabajaron en la compañía en esa época, hoy ya pensionados, que la segunda turbina que debía ser instalada se hundió en el Río Magdalena cuando era transportada desde Barranquilla hasta Tunja, y no fue posible su recuperación, razón por la cual se habilitó una turbina inglesa para su reemplazo.

La red eléctrica así lograda fue el inicio de toda la electrificación, que permite, con el aumento de

\footnotetext{
${ }^{3}$ Revista Boyacá 20 y 21, julio de 1959.
} 
termoeléctricas e hidroeléctricas, suministrar energía a los departamentos vecinos que no cuentan con un buen servicio y que le adicionan a las rentas del departamento recursos considerables ${ }^{4}$.

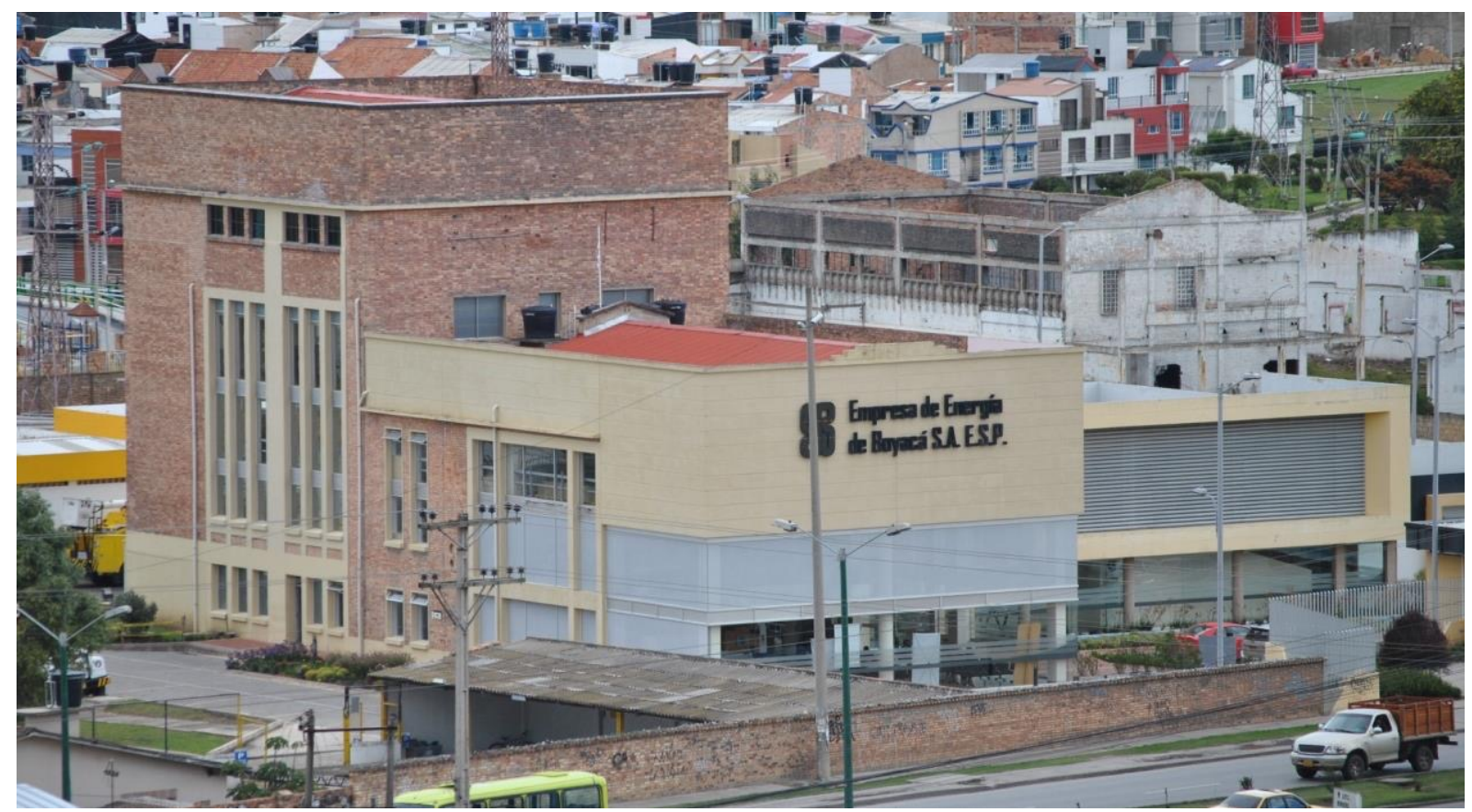

Figura 2. Parte del edificio donde se instalo la turbina alemana para la Electrificadora de Boyacá. Fuente: Armando Muñoz Luque.

Es de resaltar que a raíz de la llegada de los alemanes a Boyacá y de la instalación de las plantas eléctricas contratadas por la Gobernación, algunos municipios que tenían recursos cambiaron también sus antiguas y pequeñas plantas por otras generalmente de marca DEUS, de procedencia alemana, lo cual ayudó a su progreso industrial, como es el caso de Ramiriquí y Samacá.

\section{El caso de Cementos Boyacá}

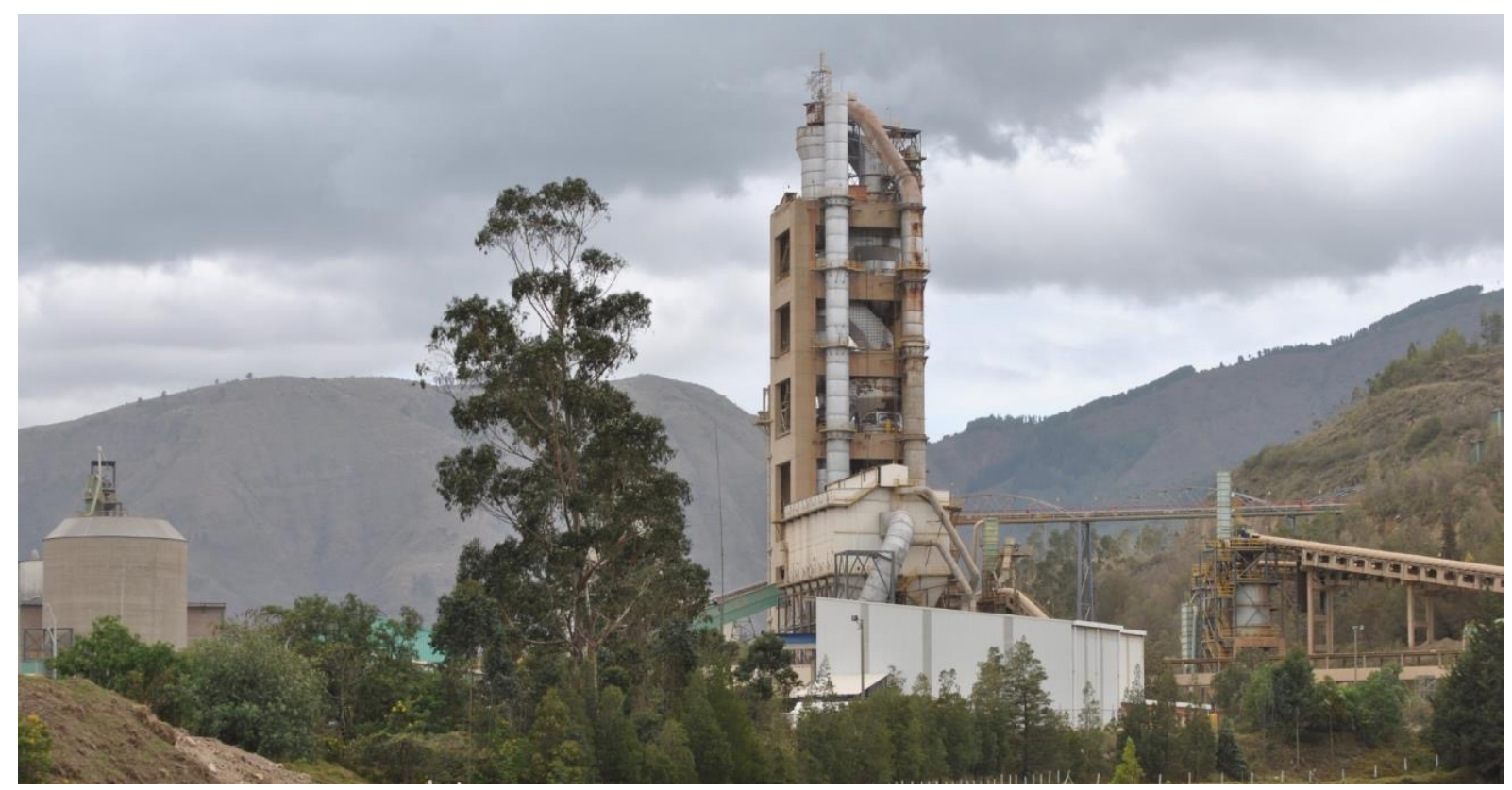

Figura 3. Cementos Boyacá, hoy Holcim, en Nobsa, Boyacá. Fuente: Armando Muñoz Luque.

${ }^{4}$ Testimonio Sr. Jesús María Sánchez G. pensionado Electrificadora de Boyacá, Julio de 2015. 
Como se anotó anteriormente, otra gran industria que floreció por esa época fue la de Cementos Boyacá, que se construyó en el municipio de Nobsa, aprovechando la coyuntura de tener la materia prima para la fabricación de cemento en las inmediaciones del lugar escogido para el montaje de la planta. Los alemanes contribuyeron con la Trituradora que hasta el presente se mantiene, con algunas modificaciones, y que es la base para la preparación de la caliza que luego se procesa en los altos hornos. Hoy en día, la fábrica se conserva casi como en sus primeros años, con una producción constante de cemento que ha sido la base para casi todas las obras de importancia en Boyacá, y que hoy se conoce con el nombre de HOLCIM, reconocida en todo el país. El aporte fundamental de los alemanes en estos casos consistió en maquinaria, equipo, tecnología y mano de obra para iniciar y apoyar la puesta en marcha de estas industrias que jalonaron significativamente el desarrollo del departamento.

\section{La historia de Acerías Paz del Río}

En 1940 se inició la construcción de Acerías Paz del Rio, proyecto muy ambicioso, para el cual ya se tenían estudios desde años anteriores, pero por falta de gestión e interés no se había podido iniciar. Como consecuencia del montaje de esta obra, se detectó el problema de la falta de energía eléctrica, de la que dependía, en buena parte, la subsistencia de la planta y que, en esa época, Boyacá no estaba en capacidad de suministrar ${ }^{5}$. Debido a esta circunstancia, simultáneamente con la construcción de Acerías Paz del Rio, se inició la modernización de la electrificación, mediante una red que cobijaría gran parte del territorio boyacense y lo enlazaría con otros departamentos del país. Casi al mismo tiempo se inicia la modernización y extensión del sistema telefónico para todos los municipios del departamento y la ampliación de la telefonía local en las principales ciudades.

El 17 de septiembre de 1948, se firmó en el Palacio Presidencial la Escritura de Constitución de la Siderúrgica Nacional de Paz del Río S.A. Al año siguiente se aceptó el proyecto inicial de la Misión Koppers, y en la cual se estipulaba una planta de 350 toneladas de producción diarias y con un presupuesto de 41 millones de dólares. Aunque el contrato inicial fue otorgado a la firma Mc Kee de Cleveland, Ohio, esta firma vinculó desde un principio ingenieros, técnicos y personal alemanes, que eran ampliamente reconocidos en todo el mundo por su experiencia lograda en yacimientos en diferentes países del mundo. Fue así, como desde su inicio, la construcción de túneles, vías, alojamientos y transporte de materiales fue dirigida por los alemanes.

Hoy en día, la empresa se mantiene en producción aunque ha atravesado por muchas dificultades económicas y administrativas; se encuentra manejada por personal netamente colombiano, aunque algunas maquinarias y equipos siguen siendo contratados con la firma de Ernest Heckels de Alemania, que provee el equipo que por daños y desgaste va saliendo de circulación.

Dentro de las obras importantes que hoy subsisten, y que día a día siguen prestando el servicio para lo que fueron construidos, está el cable aéreo, que transporta el material (hierro y carbón) desde las minas, y el cual fue inaugurado el 11 de mayo de 1954.

El transporte del carbón, inicia desde la mina localizada en la vereda La Chapa, al lado opuesto del río Chicamocha, con un recorrido de $2400 \mathrm{mts}$. Movilizando 66 vagonetas que se desplazan a una velocidad de $3 \mathrm{~m} / \mathrm{seg}$ y que transportan 180 toneladas de carbón cada hora. Este cable, esta sostenido por torres metálicas, construidas también por los alemanes y que en su mayoría se conservan hoy en día; las que han colapsado han sido reemplazadas por torres con tecnología netamente nacional, pero son una minoría.

Desde sus inicios, la construcción de las torres y el tendido del cable fueron contratados con la firma alemana Pohlig-Heckel-Bleichert, constituida por el ingeniero alemán Julius Pohlig y su socio Ernest Heckel, considerados como los pioneros de la construcción de teleféricos y quienes tenían en Siegen una empresa especializada en el diseño de equipos para minería y para siderúrgicas, desde donde habían contratado y ejecutado grandes obras relacionadas con la minería en Argentina, Brasil (Belo Horizonte y en Nova Lima) ${ }^{6}$ con un cable de 30000 metros de largo o el teleférico de Bumpur

\footnotetext{
${ }^{5}$ Wiesner Durán, Eduardo. (1963). Paz del Rio. Monografia 16, Bogotá: Universidad de los Andes.

${ }^{6} \mathrm{http}: / /$ www.pohligheckel.com.br/historia/?lan=english (31.07.15)
} 
(India) con 550 pilares o torres metálicas de soporte ${ }^{7}$. A pesar de las diferentes etapas y cambios que esta firma ha tenido desde sus comienzos, los materiales y repuestos que las instalaciones van necesitando, siguen siendo suministrados por ellos mismos, con la ventaja que la firma ha establecido una sucursal en Brasil, desde donde es más fácil traer estos repuestos que son necesarios en el buen funcionamiento de la actual planta.

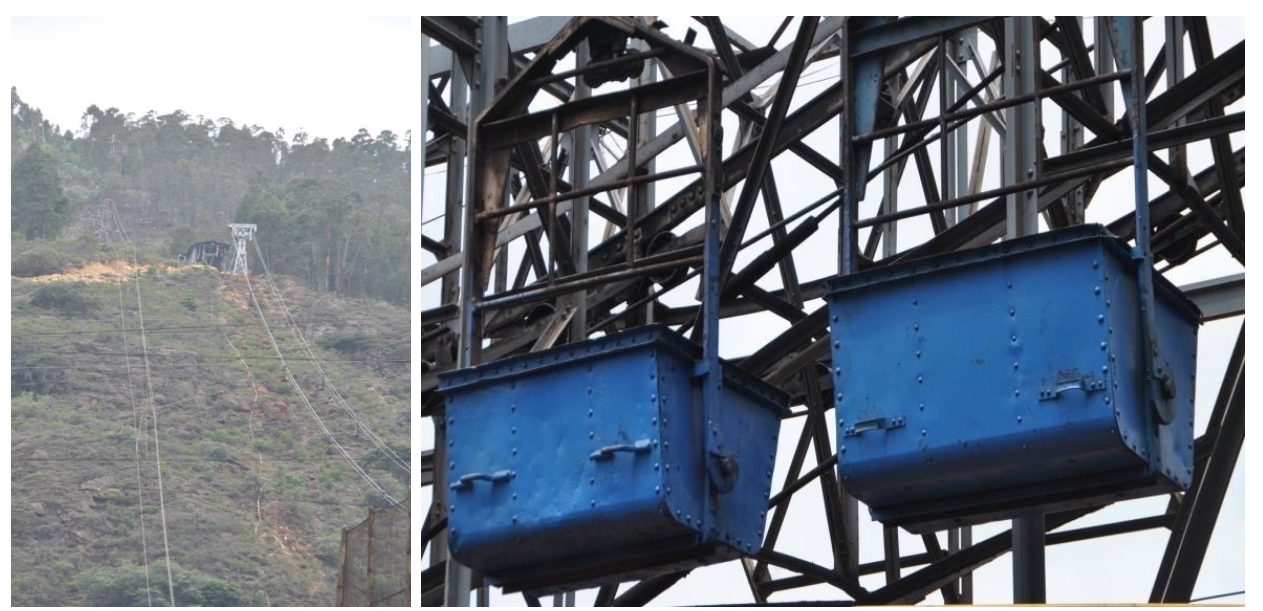

Figura 4. Cables, góndolas y torres para el transporte tanto de carbón como de mineral de hierro. Fuente: Armando Muñoz Luque.

De igual forma, original de la firma Pohlig-Heckel-Bleichert, funciona el cable para el transporte de mineral de hierro, que desde el sitio denominado La Mesa, y con un recorrido de $1040 \mathrm{mts}$, moviliza 160 toneladas cada hora, mineral que es explotado a campo abierto y que es depositado en grandes tolvas o plantas trituradoras localizadas en las afueras de Paz del Río, donde es transformado en tamaños diferentes.

En las bocas de los túneles, tanto de entrada como de salida, los alemanes construyeron también en acero unas estructuras resistentes, que hoy en día se conservan en muy buenas condiciones.

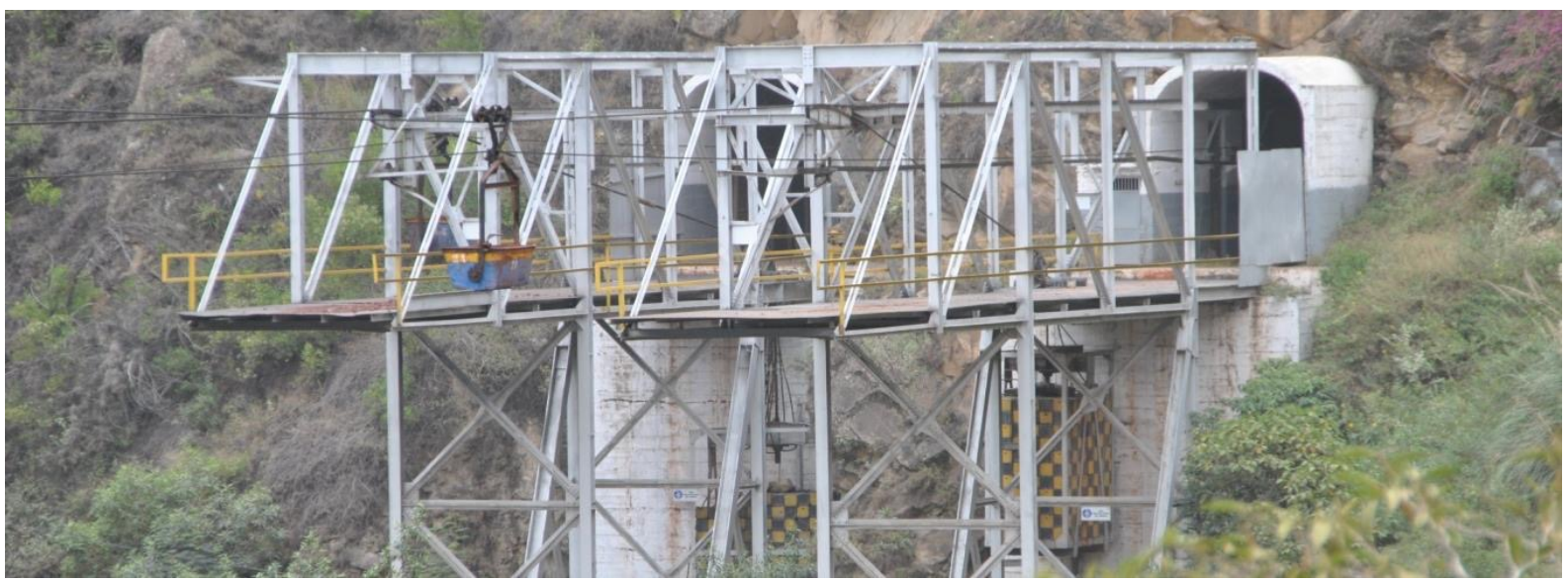

Figura 5. Entrada y Salida a los túneles con las góndolas transportadoras Fuente: Armando Muñoz Luque.

El material, que mediante estas góndolas llega a Paz del Río, es depositado en grandes tolvas de aprovisionamiento, de donde es embarcado en un ferrocarril que tiene 35 kilómetros de longitud y es llevado a Belencito, donde se encuentra la fábrica real de hierro, complementado a su vez por el material de caliza explotado en el municipio de Nobsa y que se transporta por carretera hasta las instalaciones de la fábrica.

El carbón, materia prima insustituible en la fabricación del hierro y fuente de energía para el funcionamiento del alto horno, se encuentra en grandes cantidades en la mina de La Chapa, en donde

${ }^{7}$ https://web.archive.org/web/20101105115019/http://www.cable-car.de/pohlig.htm (31.07.15) 
se han localizado yacimientos cuya cubicación probada es de 18 millones de toneladas. Además se estima que hay reservas por más de 1900 millones de toneladas. Allí en esa mina, donde se explota el carbón, se ha encontrado el mineral que reúne las condiciones de duro, brillante y limpio, se trabaja durante 24 horas diarias, con un personal de 1400 hombres, en tres túneles, dos en plena producción y el restante en desarrollo. En este subsuelo, se han cavado más de 20000 metros, entre túneles y galerías, longitud que cada mes aumenta entre 500 y 600 metros. Desde el año que se inicio la explotación La Chapa ha dado un rendimiento de más de 44.000 toneladas de carbón, rendimiento considerado excelente y logrado gracias a la técnica alemana, traída directamente del Ruhr para beneficio de la industria colombiana. (Acerías Paz del Río y el Departamento de Boyacá).

Como se dijo anteriormente, la explotación del carbón y de la piedra ferrosa, se inició con la tecnología alemana, en la construcción de túneles que se prolongaron por kilómetros dentro del subsuelo de Boyacá, y que hoy en día, aunque no están los alemanes, subsisten los túneles originales y los nuevos que se abren se hacen siguiendo esa misma tecnología. Hoy todavía subsiste un puente, construido con ese fin, solo que en la actualidad se eliminaron los rieles que servían de vía al tren, y se hizo un puente por donde circulan grandes volquetas que llevan el material hasta el lugar de recolección para cargarlo luego al tren eléctrico que lo llevará directamente a Belencito donde se realizará todo el proceso para la obtención del hierro y todos sus derivados.

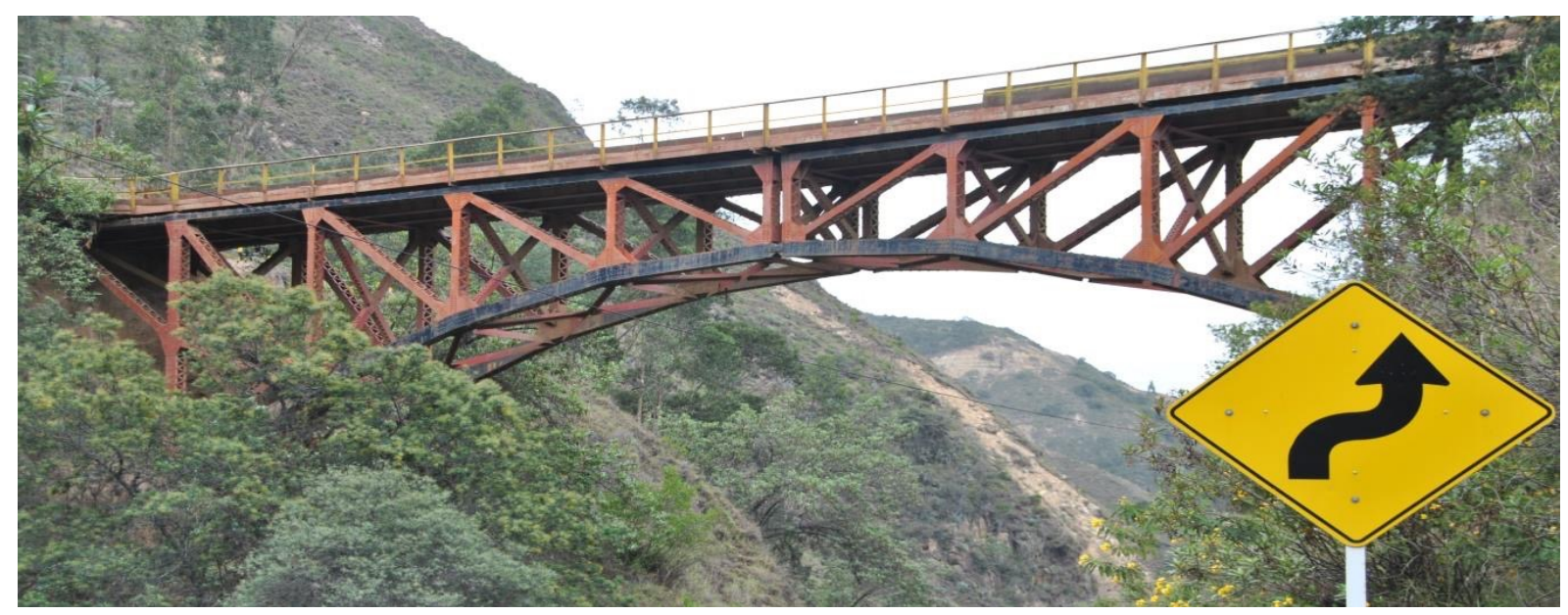

Figura 6. Puente sobre el rio Salguera que une la mina de hierro y la administración. Fuente: Armando Muñoz Luque.

No solamente la intervención alemana se concretó en montar la infraestructura de la siderúrgica, sino que también intervinieron en la planeación y construcción de las viviendas que se construyeron cerca a los yacimientos y que servían para alojar a los ingenieros y técnicos que diariamente trabajaban en la extracción del mineral. Estas viviendas, hace muchos años fueron abandonadas, cuando los extranjeros fueron terminando sus trabajos y saliendo de las plantas. El nuevo personal, en su mayoría colombianos no las ocuparon, por lo cual hoy solo se encuentran ruinas.

Caso diferente ocurrió con el barrio que estos mismos alemanes construyeron en Belencito, destinado también al personal de ingenieros y técnicos que trabajaban en la fundición de los materiales, viviendas que también fueron diseñadas y dirigidas por alemanes, con detalles y planos según costumbres y vivencias alemanas y que hoy en día se conserva, con pocas modificaciones y que sigue sirviendo de vivienda a los ingenieros y técnicos colombianos. Otra obra de gran importancia, que fue construida con materiales y mano de obra especializada alemana fue el Alto Horno, sin lugar a dudas la parte central y más importante de Acerías Paz del Rio, porque allí se depositan hierro, carbón y cal con una cocción de duración de aproximadamente 30 horas, desde el momento en que el Alto Horno es cargado y la salida del arrabio que sale a una temperatura de 1300 grados centígrados; se calcula que para obtener una tonelada de arrabio, es necesaria una carga de 2.2 toneladas de mineral de hierro, una tonelada de coque y 0.6 tonelada de caliza. Este Alto Horno del que aún se conserva gran parte, tiene 30 metros de altura, una chimenea de 82 metros, un diámetro en su parte más ancha de 5.5 metros y produce 400 toneladas diarias en promedio. 


\section{Conclusión}

En Boyacá, los ingenieros y técnicos relacionados con la instalación y puesta en marcha de las industrias no permanecieron en el lugar, ni se establecieron con sus familias en la región, como sí ocurrió en otras ciudades del país, donde hubo más arraigo y mas permanencia de familias con nexos colombianos. En Boyacá cumplieron sus contratos haciendo las obras y regresaron a sus países de origen.

Las intervenciones que tuvieron los alemanes en la industria de Boyacá, tampoco fueron muy representativas, ya que aquí no se iniciaron fábricas con capital alemán y no se instalaron familias enteras para implantar sus negocios, como en otros departamentos donde su iniciativa, sus conocimientos y sus capitales fueron fundamentales para el surgimiento de empresas muy fuertes, que con el paso de los años se consolidaron y prosperaron y que aún subsisten, como es el caso de Bavaria, Cerámicas Corona, Avianca y otras. No obstante, su aporte, como se muestra en este artículo, fue y continúa siendo, trascendental para el desarrollo del Departamento.

\section{Referencias}

Anonymus. (1970). Historia de la industria en Colombia. Revista Trimestral de la Andi 11.

Anonymus. (1959, Julio). Revista Boyacá 20 y 21.

Wiesner Durán, E. (1963). Paz del Rio. Monografia 16. Bogotá: Universidad de los Andes.

Fuentes de Internet:

Internet Archive. (2015). https://web.archive.org/web/20101105115019/http://www.cable- car.de/ pohlig.htm (31.07.15)

Pohligheckel. (2015). http://www.pohligheckel.com.br/historia/?lan=english (31.07.15)

Fuentes orales:

Testimonio Sr. Anibal Cardozo, pensionado de Telecom, Julio de 2015.

Testimonio Sr. Jesús María Sánchez G. pensionado Electrificadora de Boyacá, Julio de 2015. 